\title{
Quaternary Element Incorporation Effects on Thermal Properties and Crystal- Micro Structure of Cu-Al-Fe High Temperature Shape Memory Alloys
}

\author{
Esra BALC1 ${ }^{*}$, Sinan AKPINAR

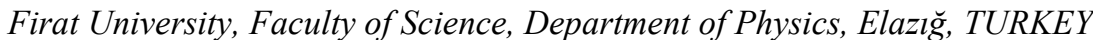 \\ "Corresponding author: E. BALCI (E-mail: balci.esra061@gmail.com)
}

Received 5 October 2020, Revised 18 March 2021, Accepted 18 April 2021

\begin{abstract}
Recently, researchers have shown an increased interest in Cu-based shape memory alloys due to their special characteristics, which can be used in high-temperature applications. In this study, ternary shape memory alloys in the form of CuAlFe with different ratios of iron and quaternary CuAlFe alloys containing $\mathrm{Ni}, \mathrm{Mn}$, and Ti were produced by arc melting. Then the produced alloys were kept at $900{ }^{\circ} \mathrm{C}$ for 24 hours to make sure that all constituents in the alloys were homogeneously distributed. The change in the transformation temperatures for all samples was checked out by Differential Scanning Calorimetry (DSC). Also, the change in the crystal structure and microstructure were determined by x-ray diffractometer (XRD) and scanning electron microscopy (SEM), respectively. The aim of this study is to compare the thermal and microstructural properties of quaternary alloys formed by adding $\mathrm{Ni}, \mathrm{Mn}$, and Ti elements to CuAlFe-based shape memory alloy with different rates, which is not available in the literature. The result of this study; although the electron concentration value increased, a significant decrease was observed in the values of the transformation temperatures. Increasing Fe-element decreased the transformation temperature non-linearly. $\mathrm{Ni}$ and $\mathrm{Mn}$ contents added to CuAlFe shape memory alloys have reduced transformation temperatures, such as $A_{f}$ and $M_{f}$.The XRD and SEM-EDX measurements showed the martensite phase with some produced compound precipitated in the matrix phase.
\end{abstract}

Keywords: CuAlFe; Shape memory alloys; crystal structure; transformation temperature; activation energy

\section{Introduction}

Nowadays, shape memory alloys (SMAs) have become more important because of their wide applications in different sectors [1-3]. Since, copper-based SMAs are easy be produced easily, relatively inexpensive, and have a shape memory effect like NiTi-based SMAs, then they have become more attractive to engineers and metallurgists [4]. In addition, these alloys have small hysteresis and exhibit good thermal and electrical conductivity [5]. Recently, the demand for high-temperature SMAs, which have transformation temperatures of more than $100{ }^{\circ} \mathrm{C}$, has rapidly increased, especially for automotive utilization [3].

Numerous studies were conducted to increase the transformation temperatures and improve some thermal/mechanical behavior of SMAs [6]. Copper-based shape memory alloys have received much attention recently due to their good ductility, ease of production and processing, and low cost. Cu-based SMAs, such as copperzinc $(\mathrm{Cu}-\mathrm{Zn})$, copper-aluminum $(\mathrm{Cu}-\mathrm{Al})$, and copper-tin (Cu-Sn) alloys have good strain recovery, easy to manufacturing, excellent thermal conductivity, and show electrical properties. Ternary $\mathrm{Cu}-\mathrm{Al}-\mathrm{Fe}$ alloys can be used for applications above $200^{\circ} \mathrm{C}$ with relatively good SME [7]. Binary $\mathrm{Cu}-\mathrm{Al}$ alloys suffer from poor cold workability and martensite stabilization; therefore, adding third or fourth additive with different rates drawbacks can improve their characteristics [8].

Among the quaternary Cu-based shape memory alloys mostly investigated, the $\mathrm{Cu}-\mathrm{Al}-\mathrm{Ni}, \mathrm{Cu}-\mathrm{Al}-\mathrm{Zn}$, and $\mathrm{Cu}-\mathrm{Al}-$ Mn alloys have been studied extensively [9]. In the literature, there are studies about adding $\mathrm{Ni}, \mathrm{Mn}, \mathrm{Be}$ to $\mathrm{CuAl}$ ${ }^{*}$ Corresponding Author shape memory alloy. For example, from the results of $\mathrm{Ni}$ addition in several studies on CuAlNi ternary shape memory alloys; Vasilenko et al. [10]. Determined the dependence of $\mathrm{Ms}$ on aluminum concentration for polycrystalline samples with 4 wt. pct Ni. Ximming et al. [10] studied the dependence of temperature on concentration in alloys with a constant value of $4.5 \mathrm{wt}$. pct $\mathrm{Ni}$ and obtained a line, the slope of which diminishes at high aluminum concentration. On the other hand, in the shape memory alloy studies of the ternary CuAlMn examined until this time, Sampath found that the grain size of $\mathrm{CuZnAl}$ SMAs can be obviously reduced by $\mathrm{Zr}$, Ti elements $[11,12]$. Even Sutou et al. reported that Si, B addition can greatly reduce the grain size of CuAlMn SMAs [13]. They also concluded that the effect of grain size on performance and the size of the grain plays an important role in the mechanical properties and energy absorption capacity. Mallik investigated the effects of different elements on the shape memory effects, transformation temperatures, and superelasticity of CuAlMn SMAs, and some possible positive results were obtained [14]. On the other hand, Lelatko et al. produced $\mathrm{Cu}_{85} \mathrm{Al}_{12.5} \mathrm{Nb}_{2} \mathrm{Ti}_{0.3} \mathrm{~B}_{0.05}$ (mass\%) shape memory alloy and other new alloys by adding $\mathrm{Ni}, \mathrm{Co}$, and $\mathrm{Cr}$ to this alloy. They found that the addition of these elements changes the transformation temperature value of austenite start temperature $[15,16]$.

In this study, some new HTSMAs were studied for irondoped $\mathrm{CuAl}$ alloy. Also, some elements such as $\mathrm{Ni}, \mathrm{Mn}$, and $\mathrm{Ti}$ were added to CuAlFe alloy to investigate thermal, mechanical behavior of the quaternary alloys However, up to now, there has been very little work systemically 
studying at these rates. Different measurements, including DSC for obtaining thermal profile, XRD for crystal structure, and SEM for crystal structure were carried out.

\section{Experimental Procedure}

The desired amounts of $\mathrm{Cu}, \mathrm{Al}, \mathrm{Fe}, \mathrm{Ni}, \mathrm{Ti}$, and $\mathrm{Mn}$ powder elements were used for preparing six different ternary and quaternary SMAs. Then the well-mixed powders were pelletized. The pellets with compositional formula: $\mathrm{Cu}_{82.7} \mathrm{Al}_{13.2} \mathrm{Fe}_{4.1}, \mathrm{Cu}_{82.2} \mathrm{Al}_{13.2} \mathrm{Fe}_{4.6}, \mathrm{Cu}_{81.7} \mathrm{Al}_{13.2} \mathrm{Fe}_{5.1}$, $\mathrm{Cu}_{80.5} \mathrm{Al}_{13.2} \mathrm{Fe}_{5.1} \mathrm{Ni}_{1.2}, \quad \mathrm{Cu}_{80.5} \mathrm{Al}_{13.2} \mathrm{Fe}_{5.1} \mathrm{Ti}_{1.2}, \quad$ and $\mathrm{Cu}_{80.5} \mathrm{Al}_{13.2} \mathrm{Fe}_{5.1} \mathrm{Mn}_{1.2}$ were labeled as CAF-1, CAF-2, CAF3, CAF-Ni, CAF-Ti, and CAF-Mn, respectively. The alloys with desired compositions are listed in Table 1 . Then, the pelletized alloys were melted in an arc melting furnace to form ingots, and they remelted several times to get a high homogeneity. The obtained alloys were kept in a furnace at $900{ }^{\circ} \mathrm{C}$ for 24 hours, and then the normalized alloys were quenched using ice-salty-water (ice-brine). The transformation temperatures and enthalpy changes of all alloys were determined using DSC with a heating-cooling rate of $20^{\circ} \mathrm{C} / \mathrm{min}$ in an argon gas atmosphere. The DSC measurements were repeated with different heating/cooling rates of $10,20,30$, and $40{ }^{\circ} \mathrm{C} / \mathrm{min}$ to calculate activation energy. The Kissinger method was used for activation energy calculations through solving the Arrhenius equation [17]. Finally, the crystal structure and consisting phases of the samples were determined by the XRD diffractometer and SEM-EDX device at room temperature.

\section{Results and Discussions}

The DSC curves of CAF-1, CAF-2, CAF-3, CAF-Ni, CAF-Ti, and CAF-Mn alloys are given in Figure 1a, and the obtained transformation temperatures are listed in Table 2, whereby, $A_{s}, A_{f}, M_{s}$, and $M_{f}$ represent austenite start, austenite final, martensite start, martensite final temperatures, respectively. It is found that the electron concentration (e/a) and adding different elements to $\mathrm{CuAlFe}$ SMA, had a dominant effect on phase transformation temperatures of the alloys. Adding Fe instead of $\mathrm{Cu}$-element in CAF-1, CAF-2, and CAF-3 ternary alloys, non-linearly diminished the value of transformation temperatures. Yang et al. [7] worked on $\mathrm{Cu}_{84-x} \mathrm{Al}_{11+x} \mathrm{Fe}_{5}$ SMAs for three samples with $(x=0,1,2)$, and they realized that the transformation temperatures were decreased with increasing Al content. Likewise, Raju and Sampath [18] Reported that a small change of Fe in the CuAlFe SMA caused a serious change in the transformation temperatures. The results of this study agree with the aforementioned studies, whereby, increased Fe-content in $\mathrm{CuAlFe}$ alloy caused a significant shift in the transformation temperature, e.g., $M_{p}$ dropped from 252.6 to $187.5^{\circ} \mathrm{C}$.

The transformation temperature values of CAF-Ni are less than CAF-1, CAF-2, and CAF-3, while corresponding temperatures in CAF-Ti alloy are higher than others. Nickel and titanium can increase the electron concentration in CAF-Ni and CAF-Ti alloys which can significantly affect on physical properties of these SMAs. The results of transformation temperatures and (e/a) are given in Table 2. The results showed that, although the electron concentration value increased, there was a significant decrease in the transformation temperatures. Similar results were reported by Zarinejad et al. [19]. Ni as a magnetic element has more impact than the manganese element. CAF-Ni alloy has lower $A_{s}$, but bigger $M_{s}$, compared with CAF-Mn alloy.
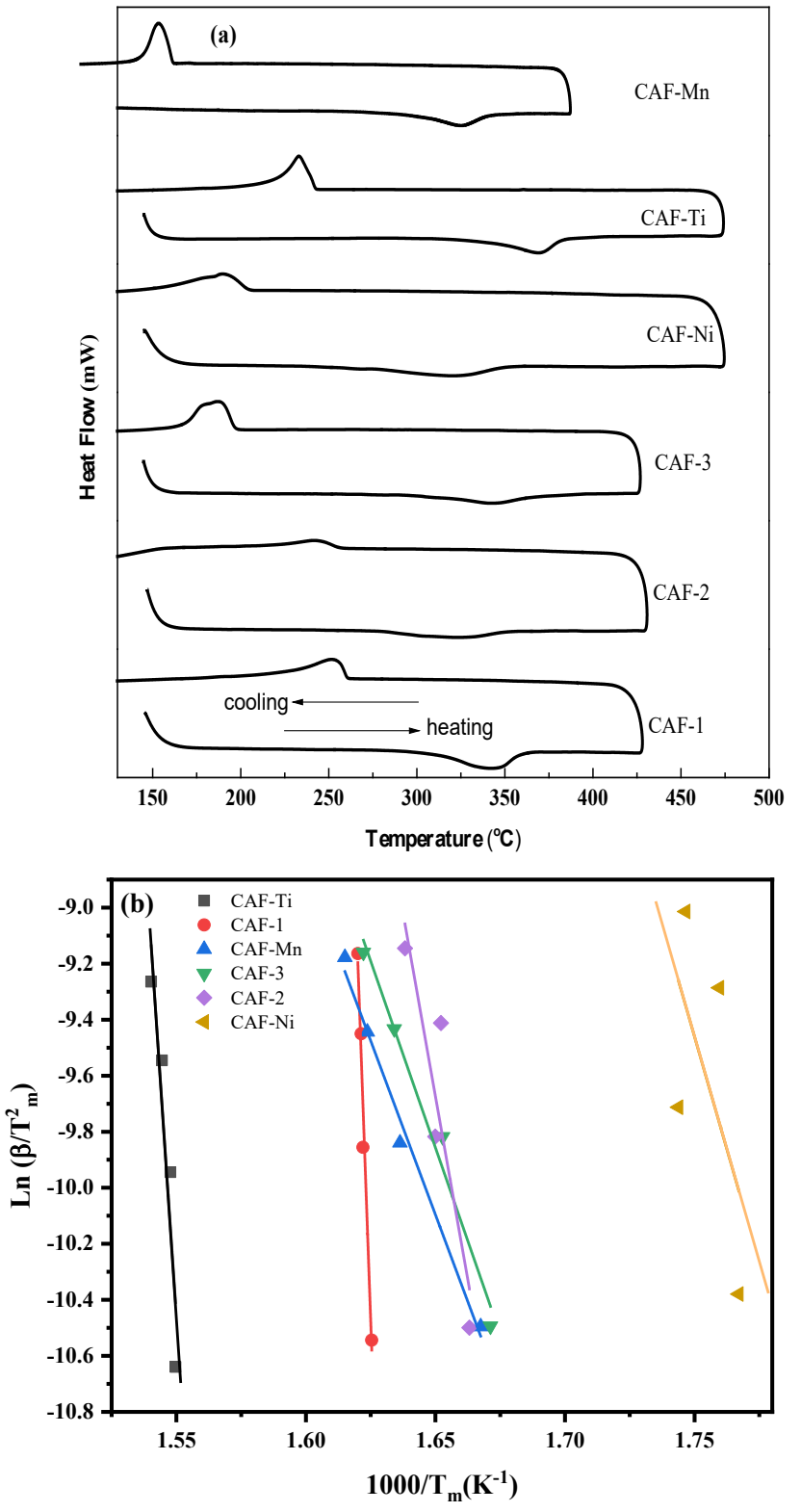

Figure 1. a) DSC graphs of all alloys. b) Activation energy curves of SMAs

Two different methods can be used to find to activation energy of the samples: one is Kissenger and the other is Ozawa method. The Kissinger equation is obtained from solving the Arrhenius equation, which can be used for calculating activation energy. The equation is expressed as follows $[20,21]$ :

$$
\ln \left(\beta / T^{2}\right)=A-E / R T
$$

where $\beta$ is the heating rate, $\mathrm{E}$ is the activation energy, $\mathrm{R}$ (= $8.314 \mathrm{~J} \cdot \mathrm{K}^{-1} \cdot \mathrm{mol}^{-1}$ ) is the ideal gas constant, $A$ is the intercept, and $T$ is the absolute temperature [22]. Using DSC results obtained and by applying Eq. (1), the activation energies are calculated and listed in Table 2 , their values are also demonstrated in Figure 1b. CAF-1 has the highest activation energy with the lowest electron concentration 
value. As the electron concentration increased, a significant reduction in the activation energy occurred. However, the combination of $\mathrm{Ti}$ in the CAF-Ti alloy has comparable higher activation energy compared to the other alloys.

Table 1. Atomic and mass ratios of the high-temperature shape memory alloys.

\begin{tabular}{|c|c|c|c|c|c|c|c|c|c|c|c|c|}
\hline \multirow{2}{*}{ Samples } & \multicolumn{6}{|c|}{ Composition (wt.\%) } & \multicolumn{6}{|c|}{ Composition (at.\%) } \\
\hline & $\mathbf{C u}$ & Al & $\mathrm{Fe}$ & $\mathbf{N i}$ & $\mathbf{T i}$ & Mn & $\mathrm{Cu}$ & Al & $\mathrm{Fe}$ & $\mathrm{Ni}$ & $\mathbf{T i}$ & Mn \\
\hline CAF-1 & 85.6 & 9.7 & $\overline{4.7}$ & $\begin{array}{ll}----- \\
\end{array}$ & $\begin{array}{ll}----- \\
\end{array}$ & $\begin{array}{ll}----- \\
\end{array}$ & 75.3 & 20 & $\overline{4.7}$ & $\begin{array}{ll}----- \\
\end{array}$ & $\begin{array}{ll}----- \\
-1\end{array}$ & 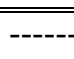 \\
\hline CAF-2 & 86.4 & 9.1 & 4.5 & ----- & ------ & ----- & 75.5 & 18.9 & 4.5 & ----- & ------ & ---- \\
\hline CAF-3 & 84.7 & 12.0 & 3.3 & ----- & ----- & ----- & 72.5 & 24.3 & 3.2 & ----- & ----- & $----\cdot$ \\
\hline CAF-Ni & 83.5 & 10.7 & 5.3 & 0.5 & ------ & ------ & 72.5 & 21.9 & 5.2 & 0.5 & ------ & ---- \\
\hline CAF-Ti & 84.7 & 12.3 & 2.5 & ------ & 0.4 & ------ & 72.3 & 24.8 & 2.4 & ------ & 0.5 & $----\cdot$ \\
\hline CAFMn & 84.7 & 11.5 & 2.6 & ------ & ----- & 1.2 & 72.9 & 23.4 & 2.5 & ----- & ------ & 1.2 \\
\hline
\end{tabular}

Table 2. Electron concentration, transformation temperatures, enthalpy change, and activation energy of the alloys.

\begin{tabular}{ccccccccccc}
\hline Alloys & \multirow{2}{\mathbf{e}/\mathbf{a}}{} & $\begin{array}{c}\boldsymbol{A}_{\boldsymbol{s}} \\
\left({ }^{\circ} \mathrm{C}\right)\end{array}$ & $\begin{array}{c}\boldsymbol{A}_{\boldsymbol{p}} \\
\left({ }^{\circ} \mathrm{C}\right)\end{array}$ & $\begin{array}{c}\boldsymbol{A}_{\boldsymbol{f}} \\
\left({ }^{\circ} \mathrm{C}\right)\end{array}$ & $\begin{array}{c}\boldsymbol{M}_{\boldsymbol{s}} \\
\left({ }^{\circ} \mathrm{C}\right)\end{array}$ & $\begin{array}{c}\boldsymbol{M}_{\boldsymbol{p}} \\
\left({ }^{\circ} \mathrm{C}\right)\end{array}$ & $\begin{array}{c}\boldsymbol{M}_{\boldsymbol{f}} \\
\left({ }^{\circ} \mathrm{C}\right)\end{array}$ & $\begin{array}{c}\Delta \mathbf{H}^{\mathbf{M} \rightarrow \mathbf{A}} \\
(\mathbf{J} / \mathbf{g})\end{array}$ & $\begin{array}{c}\Delta \mathbf{H}^{\mathbf{A} \rightarrow \mathbf{M}} \\
(\mathbf{J} / \mathbf{g})\end{array}$ & $\begin{array}{c}\mathbf{E} \\
(\mathbf{k J} / \mathbf{m o l})\end{array}$ \\
\hline \hline CAF-1 & 1.64 & 310.1 & 342.1 & 359.0 & 261.0 & 252.6 & 223.7 & 7.97 & -6.92 & 2211.8 \\
CAF-2 & 1.66 & 278.7 & 322.0 & 354.8 & 256.6 & 242.0 & 214.8 & 4.50 & -2.77 & 429.6 \\
CAF-3 & 1.67 & 298.8 & 342.9 & 364.1 & 195.6 & 187.5 & 167.5 & 8.01 & -9.51 & 221.4 \\
CAF-Ni & 1.68 & 267.9 & 320.5 & 351.2 & 204.6 & 190.4 & 154.1 & 5.83 & -6.09 & 265.6 \\
CAF-Ti & 1.76 & 317.1 & 368.6 & 383.2 & 243.4 & 233.3 & 210.5 & 11.0 & -11.4 & 1150.1 \\
CAF-Mn & 1.63 & 276.1 & 325.2 & 342.7 & 161.6 & 153.6 & 143.5 & 7.99 & -8.38 & 204.9 \\
\hline
\end{tabular}

Table 3. Equilibrium temperature, Gibbs free energy, entropy change, elastic energy calculated for CuAlFe SMAs.

\begin{tabular}{ccccccc}
\hline Alloys & $\begin{array}{c}\mathrm{T}_{\mathrm{o}} \\
(\mathrm{K})\end{array}$ & $\begin{array}{c}\Delta G^{A \rightarrow M} \\
(\mathrm{~J})\end{array}$ & $\begin{array}{c}\Delta S^{A \rightarrow M} \\
(\mathrm{~J} / \mathrm{kg} \mathrm{K})\end{array}$ & $\begin{array}{c}\Delta S^{M \rightarrow A} \\
(\mathrm{~J} / \mathrm{kg} \mathrm{K})\end{array}$ & $\begin{array}{c}G_{E} \\
(\mathrm{~J})\end{array}$ & $\begin{array}{c}\text { Temperature Hysteresis } \\
(\mathrm{K})\end{array}$ \\
\hline \hline CAF-1 & 583.1 & 669.7479 & 11.8676 & 13.66832 & 442.6616 & 98 \\
CAF-2 & 578.8 & 381.7381 & 4.785764 & 7.774706 & 200.0449 & 98.2 \\
CAF-3 & 552.95 & 1220.44 & 17.19866 & 14.48594 & 483.2824 & 168.5 \\
CAF-Ni & 551 & 775.5699 & 11.05263 & 10.58076 & 558.1579 & 146.6 \\
CAF-Ti & 586.4 & 1311.221 & 19.44065 & 18.75853 & 639.5975 & 139.8 \\
CAF-Mn & 525.25 & 1377.429 & 15.95431 & 15.2118 & 288.773 & 181.1 \\
\hline
\end{tabular}




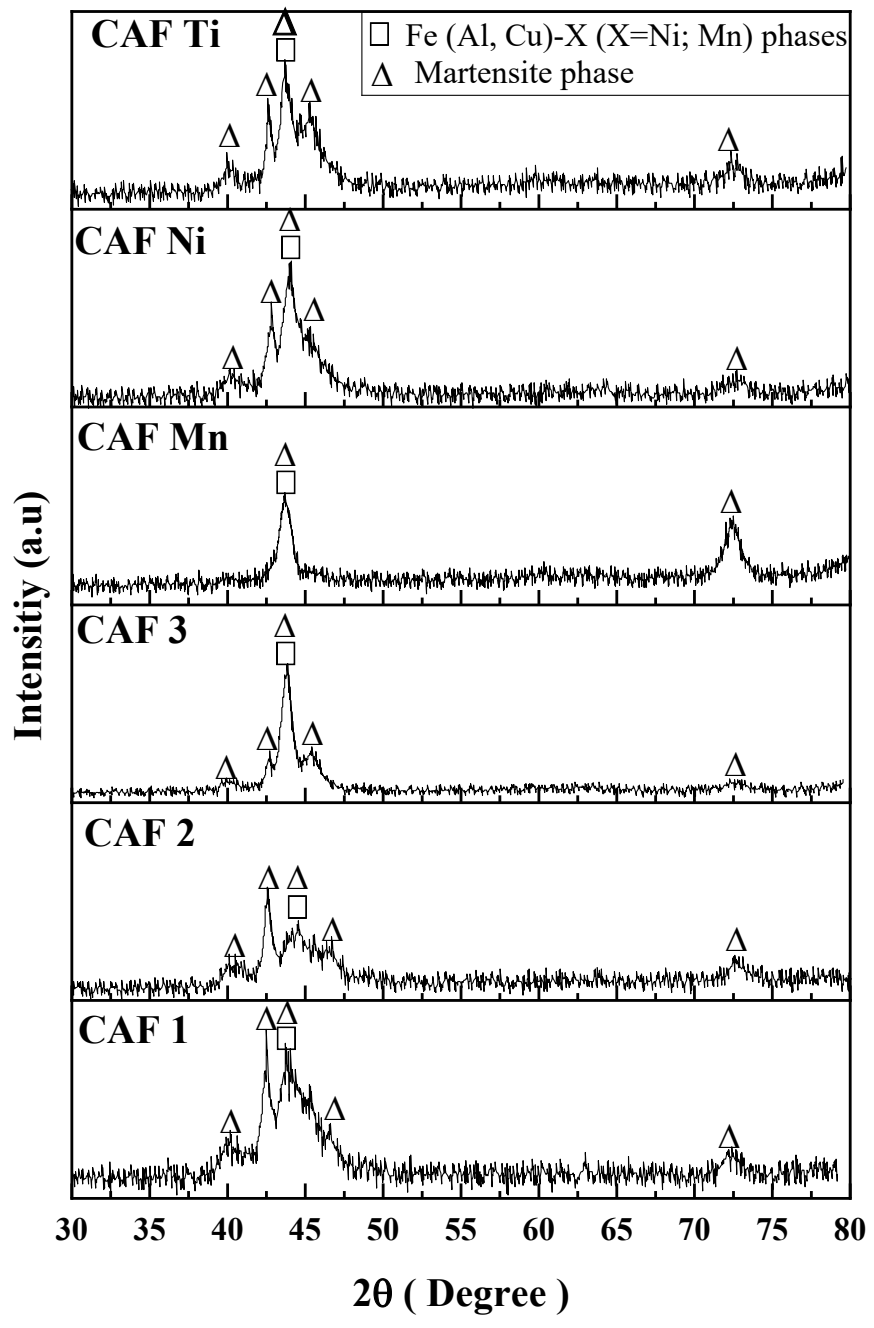

Figure 2. XRD diffractograms of CAF-Ni, CAF-Mn, and X phase for CAF-Ti alloy.

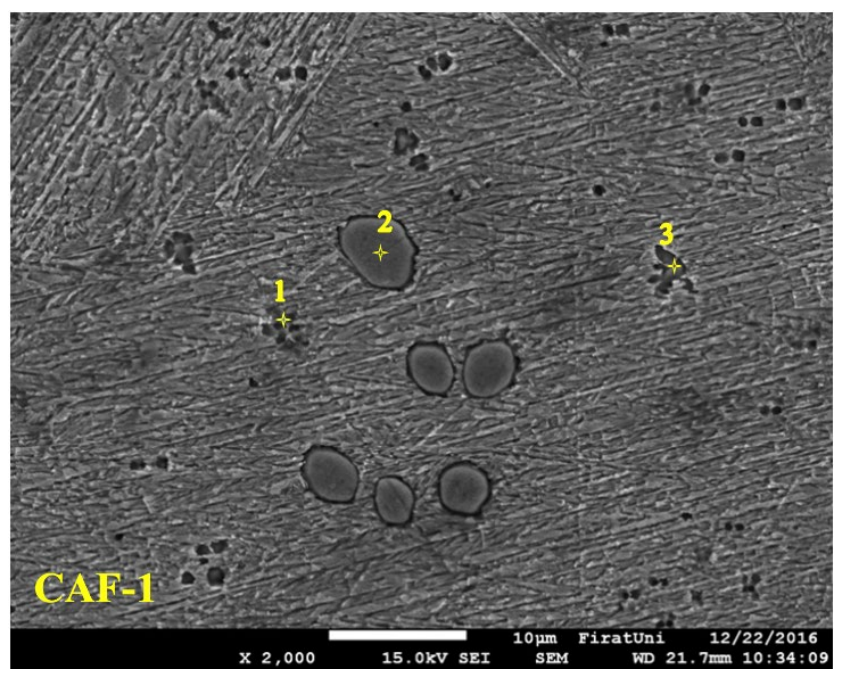

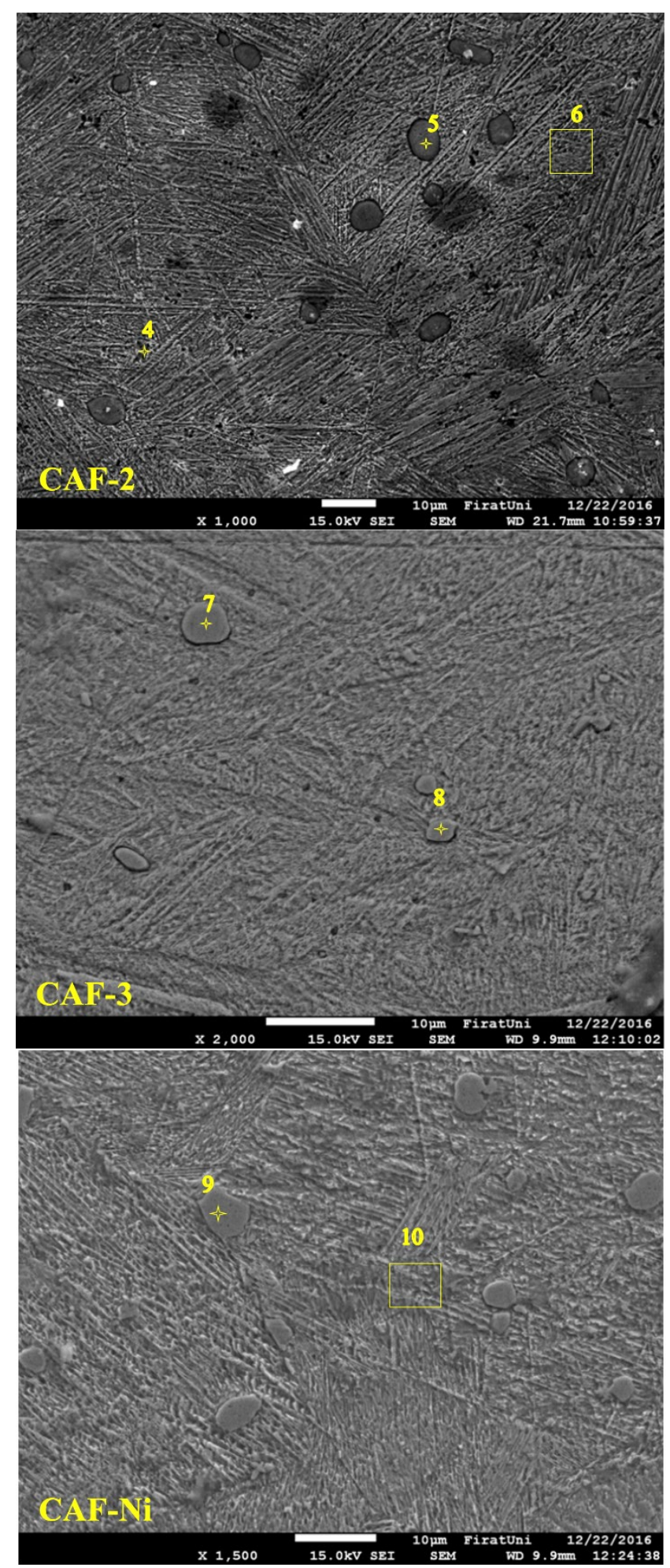

x 1,500 


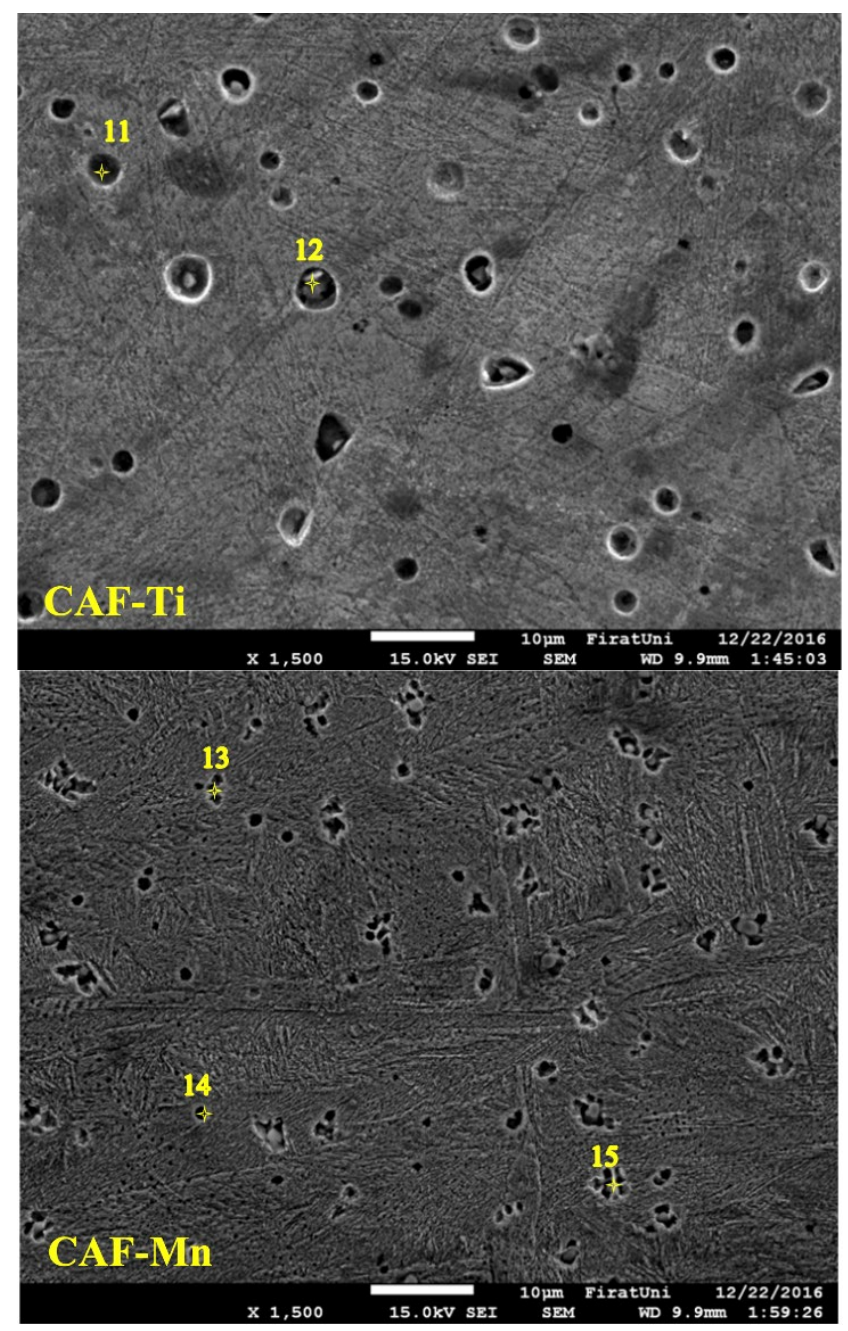

Figure 3. SEM images of produced alloys were taken at

room temperature.

The XRD measurements were accomplished at room temperature for all samples and their patterns are illustrated in Figure 2. Indexing of crystal structure of the alloys was specified using literature [23-25]. Ercan et al. determined different phases of a high temperature $\mathrm{CuAl}-\mathrm{Ta}$ shape memory alloys by analyzing XRD pattern [26]. The peaks, which represented the 18R-martensite phase, are common in all alloys. In a different study, Qader et al. found that $\mathrm{Cu}_{9} \mathrm{Al}_{4}$ precipitate phase in the XRD analysis of a $\mathrm{Cu}_{80} \mathrm{Al}_{13} \mathrm{Ni}_{3} \mathrm{Hf}_{4}$ SMA [2] . The two dominant precipitation phases are $\mathrm{Cu}_{9} \mathrm{Al}_{4}$ and $\mathrm{Cu}(\mathrm{Al}, \mathrm{Fe})$ in the CAF-1, CAF-2, and CAF-3 alloys. Also, XRD peaks showed the presence of $\mathrm{Cu}_{9} \mathrm{Al}_{4}, 18 \mathrm{R}$, and $\mathrm{Cu}(\mathrm{Al}, \mathrm{Fe})-\mathrm{Ni} / \mathrm{Mn}$ precipitate phases in CAF-Ni and CAF-Mn alloys. Furthermore, in the titanium-doped CAF-Ti alloy, each of $\mathrm{Cu}_{9} \mathrm{Al}_{4}, \mathrm{X}$-phase, and $\mathrm{Cu}$ (Al, Fe) -Ti precipitate phases were encountered [25]. According to the obtained results, the addition of Ti formed a different precipitate phase in the crystal structure of the $\mathrm{Cu}-\mathrm{Al}-\mathrm{Fe}$ alloy.

Figure 3 shows the SEM images of all samples. The precipitate phases were found in the martensite plates and the detail about the chemical composition was checked out by EDX measurements. Ercan et al. observes that the presence of martensite plates in SEM images of $\mathrm{Cu}-\mathrm{Al}$ based shape memory alloys [26]. The spectrum in CAF-1 SMA, labeled 1,2 , and 3 , represents $\mathrm{Cu}_{9} \mathrm{Al}_{4}$ phase, Fe (Al,
$\mathrm{Cu}$ ), and $\mathrm{Cu}$ (Al-Fe) phases, respectively. Similar precipitation phases were found in CAF-2 and CAF-3 samples labeled as 4-8. In the CAF-Ni alloy, spectrum 9 showed $\mathrm{Fe}(\mathrm{Al}, \mathrm{Cu})-\mathrm{Ni}$ phase, and spectrum 10 indicated $\mathrm{Cu}_{9} \mathrm{Al}_{4}$-phase. CAF-Ti alloy possesses $\mathrm{X}$-phase, which was not found in the other alloys, while $\mathrm{Cu}(\mathrm{Al}, \mathrm{Fe})$-Ti phase appeared in all samples. Finally, in the CAF-Mn alloy, Fe $(\mathrm{Cu}, \mathrm{Al})-\mathrm{Mn}, \mathrm{Cu}_{9} \mathrm{Al}_{4}$, and $\mathrm{Cu}(\mathrm{Al}, \mathrm{Fe})-\mathrm{Mn}$ precipitate phases were encountered.
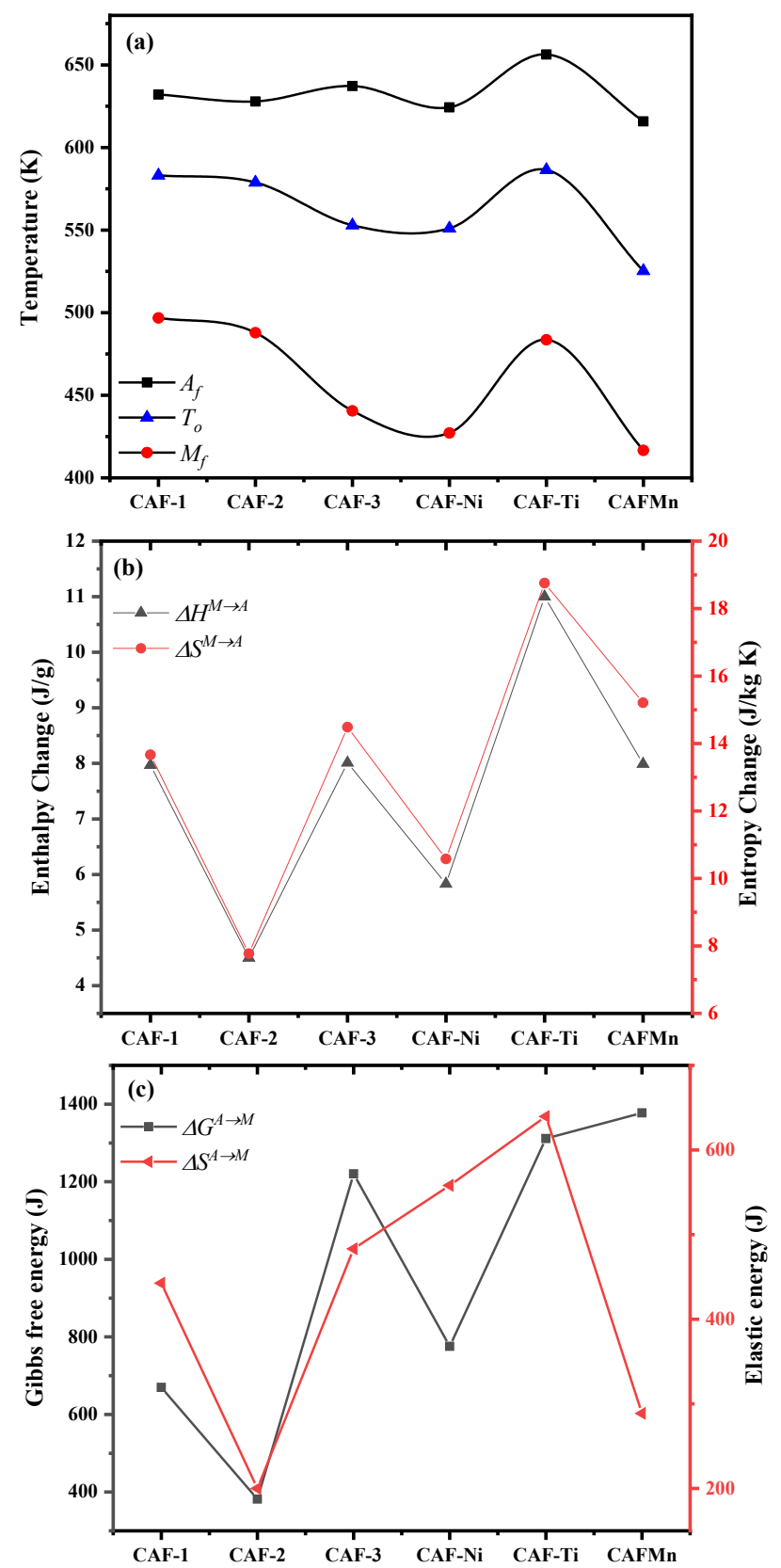

Figure 4. (a) Phase transformation temperature of different composition rates in CuAl-based alloys. (b) Enthalpy and entropy change Phase transformation temperature of different composition rates in CuAl-based alloys. (c) Gibbs free energy and elastic energies of different composition rates in CuAl-based alloys.

It is very important to define phase transformation temperatures of SMAs, which are indicated by austenite start $\left(A_{s}\right)$, austenite finish $\left(A_{f}\right)$, martensite start $\left(M_{s}\right)$, and martensite finish $\left(M_{f}\right)$ [27] because thermomechanical behavior of SMAs depends on these values [28]. The 
obtained results are revealed in Figure 4a. It can be found that the value of transformation temperatures has reduced by adding more $\mathrm{Ni}$ and $\mathrm{Mn}$ contents into $\mathrm{Cu}-\mathrm{Al}$-based

alloys. Entropy is another physical parameter that can change throughout a thermodynamic process. The entropy change in an austenite transformation process $\left(\Delta S^{M \rightarrow A}\right)$ can be calculated by the following formula [3, 29-31]:

$$
\Delta S^{M \rightarrow A}=\frac{\Delta H^{M \rightarrow A}}{T_{o}} .
$$

where $\Delta H^{M \rightarrow A}$ is the enthalpy change that was obtained for all samples by calculating the area under the endothermic DSC peaks; $T_{o}$ is equivalent temperature, where the Gibbs free energy of phase transformation is zero and is equal to $\left(M_{s}+A_{f}\right) / 2[26,32,33]$. The enthalpy is changed during martensitic phase transformation in an SMA [34]. Besides, Gibbs free energy for the martensite phase transformation is as follows [35-37]:

$\Delta G^{A \rightarrow M}\left(M_{S}\right)=-\left(T_{o}-M_{S}\right) \Delta S^{M \rightarrow A}$

The elastic energy, $G_{e}$, is another thermodynamical parameter that represents the energy saved in martensite variants, of the SMAs. Gibbs Free energy of an SMA throughout martensitic phase transformation may be a combination of changing some parameters of physical of the alloys [38]. It can be calculated by [39-41]:

$$
G_{e}=\left(M_{s}-M_{f}\right) \Delta S^{M \rightarrow A}
$$

Figure $4 \mathrm{~b}$ shows the enthalpy and calculated entropy changes of the alloys, also Figure $4 c$ exhibits the Gibbs free energy and elastic energies of CuAl-based alloys with different composition rates. Aydoğdu et al. stated that the enthalpy and entropy values calculated with the addition of $\mathrm{Co}$ element in different ratios of $\mathrm{Cu}$-Al-based shape memory alloys were in harmony [42]. The enthalpy change during the martensitic transformation, the entropy change, and the Gibbs free energy value are in harmony with each other. The results obtained are given in Table 3. Elastic energy includes elastic stress energy, substantially. This energy is the result of a change in the crystalline lattice during austenite $\leftrightarrow$ martensite transformation [43].

\section{Conclusion}

The effect of changing composition of CuAlFe shape memory alloy was investigated; moreover, $\mathrm{Ni}$, Ti, and $\mathrm{Mn}$ were added with desired amount to the ternary $\mathrm{CuAlFe}$ alloy. Thermal and microstructural analysis of the alloys was found using different characterization, which is summarized as follows:

- The different electron concentrations and the addition of various elements had a dominant effect on transformation temperatures.

- Increasing Fe-element decreased the transformation temperature non-linearly.

- Due to increasing in the electron concentration, the activation energy decreased.

- $\quad$ The XRD and SEM-EDX measurements showed that precipitation phases were encountered with the martensite-matrix phase.

- $\quad \mathrm{Ni}$ and Mn contents added to CuAlFe shape memory alloys have reduced transformation temperatures, such as $A_{f}$ and $M_{f}$.

- The value of elastic energy of the alloys was also affected by changing the compositional in the quaternary shape memory alloys.

\section{Acknowledgments:}

This work has been supported by the Management Unit of Scientific Research Projects of Firat University (FUBAP) (Project Number: FF.15.16)

\section{References:}

[1] P. M. Kadletz, P. Krooß, Y. I. Chumlyakov, M. J. Gutmann, W. W. Schmahl, H. J. Maier, T. Niendorf, "Martensite stabilization in shape memory alloysExperimental evidence for short-range ordering." Mater Lett, Vol. 159, No., pp. 16-9, 2015. doi:https://doi.org/10.1016/j.matlet.2015.06.048.

[2] I. N. Qader, M. Kök, F. Dağdelen, "Effect of heat treatment on thermodynamics parameters, crystal and microstructure of (Cu-Al-Ni-Hf) shape memory alloy." Physica B: Condensed Matter, Vol. 553, No., pp. 1-5, 2019.

[3] K. Yildiz, E. Balci, S. Akpinar, "Quenching media effects on martensitic transformation, thermodynamic and structural properties of $\mathrm{Cu}-\mathrm{Al}-\mathrm{Fe}-\mathrm{Ti}$ hightemperature shape memory alloy." J Therm Anal Calorim, Vol. 129, No. (2), pp. 937-45, 2017. doi:https://doi.org/10.1007/s10973-017-6219-2.

[4] Z. D. Cirak, M. Kök, "Investigation of the thermal and microstructural changes of CuAlNiNb quaternary shape memory alloys by different niobium amount." Eur Phys J Plus, Vol. 133, No. (7), pp. 288, 2018.

[5] K. Akash, S. M. Prabu, T. Gustmann, S. Jayachandran, S. Pauly, I. Palani, "Enhancing the life cycle behaviour of $\mathrm{Cu}-\mathrm{Al}-\mathrm{Ni}$ shape memory alloy bimorph by $\mathrm{Mn}$ addition." Materials Letters, Vol. 226, No., pp. 55-8, 2018.

[6] M. Kök, Ş. Ata, Z. D. Yakıncı, Y. Aydoğdu, "Examination of phase changes in the CuAl hightemperature shape memory alloy with the addition of a third element." J Therm Anal Calorim, Vol. 133, No. (2), pp. 845-50, 2018. doi:https://doi.org/10.1007/s10973-018-7176-0.

[7] S. Yang, Y. Su, C. Wang, X. Liu, "Microstructure and properties of $\mathrm{Cu}-\mathrm{Al}-\mathrm{Fe}$ high-temperature shape memory alloys." Mater Sci Eng B, Vol. 185, No., pp. 67-73, 2014.

[8] R. Dasgupta, "A look into Cu-based shape memory alloys: Present scenario and future prospects." J Mater Res, Vol. 29, No. (16), pp. 1681, 2014. 
[9] P. Kumar, A. K. Jain, S. Hussain, A. Pandey, R. Dasgupta, "Changes in the properties of $\mathrm{Cu}-\mathrm{Al}-\mathrm{Mn}$ shape memory alloy due to quaternary addition of different elements." Matéria (Rio de Janeiro), Vol. 20, No. (1), pp. 284-92, 2015.

memory alloys." Mettal Mater Trans A, Vol. 33, No. (8), pp. 2581-91, 2002.

[11] V. Sampath, "Improvement of shape-memory characteristics and mechanical properties of copperzinc-aluminum shape-memory alloy with low aluminum content by grain refinement." Mater Manuf Processes, Vol. 21, No. (8), pp. 789-95, 2006.

[12] V. Sampath, "Studies on the effect of grain refinement and thermal processing on shape memory characteristics of $\mathrm{Cu}-\mathrm{Al}-\mathrm{Ni}$ alloys." Smart Mater Struct, Vol. 14, No. (5), pp. S253, 2005.

[13] Y. Sutou, T. Omori, N. Koeda, R. Kainuma, K. Ishida, "Effects of grain size and texture on damping properties of $\mathrm{Cu}-\mathrm{Al}-\mathrm{Mn}$-based shape memory alloys." Mater Sci Eng, A, Vol. 438, No., pp. 743-6, 2006.

[14] U. Mallik, V. Sampath, "Influence of quaternary alloying additions on transformation temperatures and shape memory properties of $\mathrm{Cu}-\mathrm{Al}-\mathrm{Mn}$ shape memory alloy." J Alloys Compd, Vol. 469, No. (1-2), pp. 156-63, 2009.

[15] J. Lelatko, H. Morawiec, "The effect of Ni, Co and $\mathrm{Cr}$ on the primary particle structure in $\mathrm{Cu}-\mathrm{Al}-\mathrm{Nb}-\mathrm{X}$ shape memory alloys." Mater chem phys, Vol. 81, No. (2-3), pp. 472-5, 2003.

[16] J. Lelatko, H. Morawiec, "The modeling of the deformation behavior of $\mathrm{Cu}-\mathrm{Al}-\mathrm{Nb}-\mathrm{X}$ shape memory alloys containing primary particles." Mater Sci Eng, A, Vol. 481, No., pp. 684-7, 2008.

[17] R. L. Blaine, H. E. Kissinger, "Homer Kissinger and the Kissinger equation." Thermochim Acta, Vol. 540, No., pp. 1-6, 2012.

[18] T. Raju, V. Sampath, "Influence of aluminium and iron contents on the transformation temperatures of $\mathrm{Cu}-\mathrm{Al}-\mathrm{Fe}$ shape memory alloys." T Indian I Metals, Vol. 64, No. (1-2), pp. 165, 2011.

[19] M. Zarinejad, Y. Liu, "Dependence of Transformation Temperatures of NiTi-based Shape-Memory Alloys on the Number and Concentration of Valence Electrons." Adv Funct Mater, Vol. 18, No. (18), pp. 2789-94, 2008.

[20] M. Kök, K. Yildiz, "Oxidation parameters determination of $\mathrm{Cu}-\mathrm{Al}-\mathrm{Ni}-\mathrm{Fe}$ shape-memory alloy at high temperatures." Appl Phys A, Vol. 116, No. (4), pp. 2045-50, 2014. doi:https://doi.org/10.1007/s00339-014-8394-3.

[21] E. Acar, M. Kok, I. Qader, "Exploring surface oxidation behavior of NiTi-V alloys." Eur Phys J Plus, Vol. 135, No. (1), pp. 58, 2020. doi:https://doi.org/10.1140/epjp/s13360-019-00087y.

[22] J. Vazquez, P. Lopez-Alemany, P. Villares, R. Jimenez-Garay, "Generalization of the Avrami
[10] V. Recarte, R. Pérez-Sáez, J. San Juan, E. Bocanegra, M. Nó, "Influence of $\mathrm{Al}$ and $\mathrm{Ni}$ concentration on the martensitic transformation in $\mathrm{Cu}-\mathrm{Al}-\mathrm{Ni}$ shape-

equation for the analysis of non-isothermal transformation kinetics. Application to the crystallization of the Cu0. 20As0. 30Se0. 50 alloy." J Phys Chem Solids, Vol. 61, No. (4), pp. 493-500, 2000.

[23] Z. Wei, H. Peng, W. Zou, D. Yang, "Aging effects in a Cu-12Al-5Ni-2Mn-1Ti shape memory alloy." Mettal Mater Trans A, Vol. 28, No. (4), pp. 955-67, 1997.

[24] I. Hurtado, P. Ratchev, J. Van Humbeeck, L. Delaey, "A fundamental study of the $\chi$-phase precipitation in CuAlNiTi (Mn) shape memory alloys." Acta Mater, Vol. 44, No. (8), pp. 3299-306, 1996.

[25] K. Sugimoto, K. Kamei, H. Matsumoto, S. Komatsu, K. Akamatsu, T. Sugimoto, "Grain-refinement and the related phenomena in quaternary $\mathrm{Cu}-\mathrm{Al}-\mathrm{Ni}$-Ti shape memory alloys." Le Journal de Physique Colloques, Vol. 43, No. (C4), pp. C4-761-C4-6, 1982.

[26] E. Ercan, F. Dagdelen, I. Qader, "Effect of tantalum contents on transformation temperatures, thermal behaviors and microstructure of CuAlTa HTSMAs." J Therm Anal Calorim, Vol. 139, No. (1), pp. 29-36, 2020.

[27] S. S. Mohammed, M. Kök, Z. D. Çirak, I. N. Qader, F. Dağdelen, H. S. A. Zardawi, "The Relationship between Cobalt Amount and Oxidation Parameters in NiTiCo Shape Memory Alloys." PMM, Vol. 121, No. (14), pp. 1411-7, 2020. doi:10.1134/S0031918X2013013X.

[28] K. Melton, O. Mercier, "The mechanical properties of NiTi-based shape memory alloys." Acta Metall, Vol. 29, No. (2), pp. 393-8, 1981.

[29] C. Tatar, R. Acar, I. N. Qader, "Investigation of thermodynamic and microstructural characteristics of NiTiCu shape memory alloys produced by arc-melting method." Eur Phys J Plus, Vol. 135, No., pp. 311, 2020. doi:https://doi.org/10.1140/epjp/s13360-02000288-w.

[30] F. Dagdelen, B. Esra, I. N. Qader, E. Ozen, M. Kok, M. S. Kanca, S. S. Abdullah, S. S. Mohammed, "Influence of the $\mathrm{Nb}$ Content on the Microstructure and Phase Transformation Properties of NiTiNb Shape Memory Alloys." JOM, Vol. 72, No., pp. 1664-72, 2020. doi:https://doi.org/10.1007/s11837-020-040266.

[31] M. Kok, A. O. A. Al-Jaf, Z. D. Çirak, I. N. Qader, E. Özen, "Effects of heat treatment temperatures on phase transformation, thermodynamical parameters, crystal microstructure, and electrical resistivity of NiTiV shape memory alloy." J Therm Anal Calorim, Vol. 139, No., pp. 3405-13, 2020. doi:https://doi.org/10.1007/s10973-019-08788-3.

[32] F. Dagdelen, M. Kok, I. Qader, "Effects of Ta content on thermodynamic properties and transformation 
temperatures of shape memory NiTi alloy." Met Mater Int, Vol. 25, No. (6), pp. 1420-7, 2019. doi:https://doi.org/10.1007/s12540-019-00298-z.

[33] M. Kök, I. N. Qader, S. S. Mohammed, E. ÖNER, F. Dağdelen, Y. Aydogdu, "Thermal Stability and Some Thermodynamics Analysis of Heat Treated biocompatibility assessment of quaternary NiTiNbV SMA." The European Physical Journal Plus, Vol. 136, No. (2), pp. 1-13, 2021.

[35] S. S. Mohammed, M. Kok, I. N. Qader, M. S. Kanca, E. Ercan, F. Dagdelen, Y. Aydogdu, "Influence of Ta Additive into Cu84-xAl13Ni3 (wt\%) Shape Memory Alloy Produced by Induction Melting." Iran J Sci Technol A, Vol. 44, No., pp. 1167-75, 2020. doi:https://doi.org/10.1007/s40995-020-00909-0.

[36] M. Kök, H. S. A. Zardawi, I. N. Qader, M. S. Kanca, "The effects of cobalt elements addition on Ti2Ni phases, thermodynamics parameters, crystal structure and transformation temperature of NiTi shape memory alloys." Eur Phys J Plus, Vol. 134, No. (5), pp. 197, 2019. doi:https://doi.org/10.1140/epjp/i2019-125709.

[37] E. Balci, F. Dagdelen, I. N. Qader, M. Kok, "Effects of substituting $\mathrm{Nb}$ with $\mathrm{V}$ on thermal analysis and biocompatibility assessment of quaternary NiTiNbV SMA." Eur Phys J Plus, Vol. 136, No. (2), pp. 145, 2021. doi:10.1140/epjp/s13360-021-01149-w.

[38] J.-Y. Gauthier, C. Lexcellent, A. Hubert, J. Abadie, N. Chaillet, "Modeling rearrangement process of martensite platelets in a magnetic shape memory alloy $\mathrm{Ni} 2 \mathrm{MnGa}$ single crystal under magnetic field and (or) stress action." JIMSS, Vol. 18, No. (3), pp. 289-99, 2007.

doi:https://doi.org/10.1177/1045389X06066094.
Quaternary CuAlNiTa Shape Memory Alloy." Mater Res Express, Vol. 7, No., pp., 2020. doi:https://doi.org/10.1088/2053-1591/ab5bef.

[34] E. Balci, F. Dagdelen, I. N. Qader, M. Kok, "Effects of substituting $\mathrm{Nb}$ with $\mathrm{V}$ on thermal analysis and

[39] I. N. Qader, E. Ercan, B. A. M. Faraj, M. Kok, F. Dagdelen, Y. Aydogdu, "The Influence of TimeDependent Aging Process on the Thermodynamic Parameters and Microstructures of Quaternary Cu79Al12-Ni4-Nb5 (wt\%) Shape Memory Alloy." Iran J Sci Technol A, Vol. 44, No., pp. 903-10, 2020. doi:https://doi.org/10.1007/s40995-020-00876-6.

[40] C. Tatar, S. Kazanc, "Investigation of the effect of pressure on thermodynamic properties and thermoelastic phase transformation of CuAlNi alloys: A molecular dynamics study." CAP, Vol. 12, No. (1), pp. 98-104, 2012.

[41] I. N. Qader, M. Kok, Z. D. Cirak, "The effects of substituting $\mathrm{Sn}$ for $\mathrm{Ni}$ on the thermal and some other characteristics of NiTiSn shape memory alloys." J Therm Anal Calorim, Vol., No., pp., 2020. doi:https://doi.org/10.1007/s10973-020-09758-w.

[42] Y. Aydoğdu, F. Kürüm, M. Kök, Z. D. Yakinci, A. Aydoğdu, "Thermal properties, microstructure and microhardness of $\mathrm{Cu}-\mathrm{Al}-\mathrm{Co}$ shape memory alloy system." Transactions of the Indian Institute of Metals, Vol. 67, No. (4), pp. 595-600, 2014.

[43] K. Nurveren, A. Akdoğan, W. Huang, "Evolution of transformation characteristics with heating/cooling rate in NiTi shape memory alloys." J Mater Process Technol, Vol. 196, No. (1-3), pp. 129-34, 2008. 